\title{
BMJ Open Educational differences in sickness absence trends among young employees from 2002 to 2013 in Helsinki, Finland
}

\author{
Hilla Sumanen, Eero Lahelma, Jouni Lahti, Olli Pietiläinen, Ossi Rahkonen
}

To cite: Sumanen $\mathrm{H}$, Lahelma E, Lahti J, et al. Educational differences in sickness absence trends among young employees from 2002 to 2013 in Helsinki, Finland. BMJ Open 2016;6:e008550. doi:10.1136/bmjopen-2015008550

- Prepublication history for this paper is available online. To view these files please visit the journal online (http://dx.doi.org/10.1136/ bmjopen-2015-008550).

Received 21 April 2015 Revised 22 January 2016 Accepted 20 April 2016

CrossMark

Department of Public Health, University of Helsinki, Helsinki, Finland

Correspondence to Hilla Sumanen; hilla. sumanen@helsinki.fi

\section{ABSTRACT}

Objective: Socioeconomic differences in sickness absence $(\mathrm{SA})$ are well established among older employees but poorly understood among the young. Our aim was to examine 12-year trends in educational differences in SA among young female and male employees, and to assess the magnitude of the differences.

Design: We examined annual SA spells. The data were obtained from the employer's registers and linked to Statistics Finland's register data on completed education and qualifications. Education was classified into four hierarchical groups. Joinpoint regression models were used to identify turning points in SA trends. The magnitude of the relative educational differences was estimated in accordance with the relative index of inequality for 2002, 2008 and 2013.

Setting: Employees of the City of Helsinki, Finland, in 2002-2013.

Participants: The analyses covered female and male employees aged 25-34 years: employees aged 35-54 years were used as a reference group.

Outcome: SA spells.

Results: An educational gradient emerged among younger and older women and men. SA spells increased in the early 2000s, and downward turning points were located in 2007-2010 in all educational groups among women and in most groups among men. The magnitude of the differences remained broadly stable among younger women from 2002 to 2013, and decreased slightly among older women and more strongly among younger and older men. The educational differences were greater among men than women in the early 2000s, but similar among both at the end of the study period.

Conclusions: The changes in SA spells may reflect the economic downturn started in 2008 and resulting job insecurity. Early preventive measures aimed at reducing educational differences in SA should be focused at an early stage on those with low levels of education in particular.

\section{INTRODUCTION}

There is a wealth of evidence indicating socioeconomic differences in sickness absence (SA) among older employees, ${ }^{1-6}$ but

\section{Strengths and limitations of this study}

- The study was based on a large number of employees aged 25-34 years, and educational differences in sickness absence were examined over 12 years.

- Complete and accurate registers were used to obtain data on employees' qualifications and sickness absence.

- Education was used as a measure of socioeconomic position. Education is hierarchical and determined in early adulthood.

- Turning points in recent sickness absence trends were identified.

- The registers used lacked further information on the participants.

studies among younger employees are still scarce. Educational level is a key dimension of socioeconomic position and primarily indicates differences in non-material resources such as knowledge, skills, values and attitudes. As such, it contributes to health-related behaviours ${ }^{4} 78$ in that employees who are more highly educated are likely to have the resources to make healthier lifestyle choices. ${ }^{9}$

We have shown in our previous studies that educational level is a strong independent determinant of SA among young employees, and that those on the lower levels are more at risk. ${ }^{10}$ Focusing on employees aged 2559 years, we also found that absolute differences in SA between educational groups widened during the 1990 s. $^{4}$ However, little is known about more recent trends. Further information about educational differences in SA among young employees is needed to determine whether the differences are narrowing or widening. Such evidence would help the targeting of preventive measures and the focusing of resources effectively at an early stage, given that young adults entering working life play a key role in extending working careers and SA might challenge its positive development. ${ }^{11}$ We examined trends 
in educational differences in SA among young female and male employees aged 25-34 years covering the period from 2002 to 2013. In addition, we examined the magnitude of the relative educational differences in SA among young employees in 2002, 2008 and 2013. Older employees aged 35-54 years were used as a reference group. We expected to find educational differences in SA, which also remain over time. ${ }^{4} 10$

\section{MATERIAL AND METHODS}

Data

This study is part of the Helsinki Health Study on health and well-being among employees of the City of Helsinki, Finland. Helsinki is the capital of Finland, and the municipality is the largest employer in the country, with approximately 40000 employees in wide range of whitecollar and blue-collar occupations. Its main areas of operation include healthcare, education, social welfare services, public transport, culture, construction and technical services. All employees are covered by the same personnel administration and registration systems and SA policies, which did not change much during the study period. All employees have access to occupational healthcare services. ${ }^{12}$ There were more women than men in the data (table 1), which is typical of the municipal sector in Finland.

\section{Measures}

We used the City of Helsinki's personnel and SA registers to obtain individual-level information on SA and sociodemographic factors. The registers cover all employees, their work contracts and SA spells to an accuracy of 1 day. ${ }^{4}$

All permanently and temporarily employed staff in 2002-2013 and aged 25-34 and 35-54 years were initially included in the analyses (table 1). Employees working for $<28 \mathrm{~h}$ a week and those with no registered income (being on leave or for other reasons) were excluded.

SA spells per 100 person-years were calculated annually. SA spell means the period when employee is out of work due to illness. According to the practice of the City of Helsinki, employees may be on self-certified SA up to 3 days, after that a medical certificate is mandatory. Consecutive and overlapping SA spells were combined. All interruptions in employment for reasons other than the employee's own illness, such as a work injury or caring for a sick child, were excluded from the analyses.

Information on education was obtained from Statistics Finland's register of completed education and qualifications ${ }^{13}$ and was linked to the City of Helsinki's register data. Education was classified into four hierarchical levels annually according to the highest completed qualification: ${ }^{13}$ basic education (comprehensive school), lower secondary (upper secondary school, vocational school), upper secondary (a bachelor's degree from a university or institution of applied sciences) and higher education (a master's or doctoral degree). Educational qualifications are required in many municipal occupations. Employees with basic education usually work in lower occupational positions, with jobs such as bus drivers, cleaners and maintenance workers. Typical jobs for lower secondary

Table 1 Descriptive statistics on employees aged 25-34 and 35-54 years of the City of Helsinki, Finland, in 2002, 2008 and 2013

\begin{tabular}{|c|c|c|c|c|c|c|}
\hline & \multicolumn{2}{|l|}{2002} & \multicolumn{2}{|l|}{2008} & \multicolumn{2}{|l|}{2013} \\
\hline & $\mathbf{N}$ & Per cent & $\bar{N}$ & Per cent & $\mathbf{N}$ & Per cent \\
\hline \multicolumn{7}{|l|}{ Age 25-34 } \\
\hline Women & 6108 & & 5558 & & 6201 & \\
\hline Higher & 528 & 8.6 & 714 & 12.9 & 960 & 15.5 \\
\hline Upper secondary & 2424 & 39.7 & 2109 & 37.9 & 2507 & 40.4 \\
\hline Lower secondary & 2682 & 43.9 & 2395 & 43.1 & 2453 & 39.6 \\
\hline Basic & 474 & 7.8 & 340 & 6.1 & 281 & 4.5 \\
\hline Men & 1707 & & 1736 & & 2044 & \\
\hline Higher & 144 & 8.5 & 178 & 10.2 & 238 & 11.6 \\
\hline Upper secondary & 405 & 23.7 & 362 & 20.9 & 489 & 23.9 \\
\hline Lower secondary & 888 & 52.0 & 971 & 55.9 & 1140 & 55.8 \\
\hline Basic & 270 & 15.8 & 225 & 13.0 & 177 & 8.7 \\
\hline \multicolumn{7}{|l|}{ Age 35-54 } \\
\hline Women & 15517 & & 14784 & & 13828 & \\
\hline Higher & 1723 & 11.1 & 2034 & 13.8 & 2213 & 16.0 \\
\hline Upper secondary & 4937 & 31.8 & 5078 & 34.4 & 5010 & 36.2 \\
\hline Lower secondary & 6431 & 41.5 & 6054 & 40.9 & 5497 & 39.8 \\
\hline Basic & 2426 & 15.6 & 1618 & 10.9 & 1108 & 8.0 \\
\hline Men & 4613 & & 4557 & & 4692 & \\
\hline Higher & 704 & 15.3 & 755 & 16.6 & 777 & 16.6 \\
\hline Upper secondary & 1057 & 22.9 & 1098 & 24.1 & 1193 & 25.4 \\
\hline Lower secondary & 1912 & 41.4 & 1949 & 42.7 & 2110 & 45.0 \\
\hline Basic & 940 & 20.4 & 755 & 16.6 & 612 & 13.0 \\
\hline
\end{tabular}


education are practical nurse and secretary, and for upper secondary education nurse or foreman. Higher education is required in jobs such as teacher or doctor.

\section{Statistical methods}

We analysed women and men separately given the differences in SA trends, and conducted separate analyses for both age groups. Age was adjusted for using data from 2008 as the standard population. Joinpoint regression modelling ${ }^{14}$ was used to identify major changes, in other words, turning points in SA trends. Several different trend lines are connected together at the turning points in joinpoint models. The modelling starts with a linear trend line, with zero turning points, and then tests whether there are turning points that are statistically significant and should be added. We specified the maximum number of turning points as 2 based on a preliminary visual examination of the SA trends. The statistical significance of a change in the trend was assessed by means of Monte Carlo permutation. Annual percentage changes, an estimated constant percentage change per year, were calculated from the joinpoint models for the identified trend periods. Annual percentage changes and their 95\% CIs are presented for each identified period. The Joinpoint Regression Program V.4.1.1 was used for the analyses. ${ }^{15}$

Relative index of inequality (RII) values adjusted for age and their $95 \%$ CIs were calculated to determine the magnitude of the relative educational differences in SA spells. The original values of each educational group were replaced with the midpoint of the cumulative proportion and ranked between 0 and 1 , thus hypothetically representing the best-off and worst-off people in the population in terms of education. These indicators were then used as continuous variables in the negative binomial regression models. The logarithm of the number of days employed was used as the offset to take different lengths of employment into account. RII imposes linearity on the associations between education and SA spells, and the resulting value could be interpreted as the rate ratio for having SA at the bottom compared to the risk at the top of the educational hierarchy. RII values above 1.0 indicate higher SA rates in the lower educational groups, and values below 1.0 indicate reverse differences. ${ }^{16}$

\section{RESULTS}

Table 1 presents the descriptive statistics for the years 2002, 2008 and 2013. Lower and upper secondary were the most common educational levels among younger and older women, whereas lower secondary was the most common level among younger and older men.

The more highly educated had fewer SA spells than those with a lower level education in the two age groups, as well as among women and men (table 2). In all the educational groups, younger women and men had more SA spells than older women and men, and women had more spells than men.

\section{Educational differences in SA trends among women}

Age-adjusted SA followed a gradient in that among younger and older women, those with a basic education had the highest amount of SA and the most highly educated had the least (figure 1). The amount of SA increased for each educational group at the beginning of the study period but decreased towards the end. Joinpoint regression models (table 3 and figure 1) confirmed that the turning points in the trends were located in the years 2008-2010 in each educational group among younger and older women. The strongest increase $(4.1 \%$ annually, CI 2.2 to 5.9) was among the most highly educated younger women between 2002 and 2010 (table 3). The amount of SA decreased towards the end of the study period in each educational group and both age groups. The strongest decrease $(-5.1 \%$ annually, CI -9.1 to -0.8 ) was between 2010 and 2013 among younger women with an upper secondary education.

The magnitude of the relative educational differences in SA, measured in terms of age-adjusted RII values, remained broadly stable among younger women during the study period: 2.20 (95\% CI 1.96 to 2.47 ) in 2002, 2.44 (95\% CI 2.16 to 2.76) in 2008 and 2.31 (95\% CI 2.06 to 2.60) in 2013 (table 4). There was a slight decrease among older women from 2002 to 2013.

Table 2 Average sickness absence spells/100 person-years by educational group in 2002, 2008 and 2013

\begin{tabular}{|c|c|c|c|c|c|c|}
\hline \multirow[b]{2}{*}{ Year } & \multicolumn{3}{|c|}{ Women } & \multicolumn{3}{|l|}{ Men } \\
\hline & 2002 & 2008 & 2013 & 2002 & 2008 & 2013 \\
\hline \multicolumn{7}{|l|}{ Age 25-34 } \\
\hline Higher & 168 & 215 & 214 & 132 & 176 & 127 \\
\hline Upper secondary & 289 & 324 & 285 & 183 & 262 & 197 \\
\hline Lower secondary & 355 & 422 & 385 & 254 & 298 & 255 \\
\hline Basic & 477 & 512 & 457 & 352 & 375 & 316 \\
\hline \multicolumn{7}{|l|}{ Age 35-54 } \\
\hline Higher & 157 & 193 & 186 & 114 & 128 & 138 \\
\hline Upper secondary & 237 & 287 & 276 & 142 & 204 & 179 \\
\hline Lower secondary & 309 & 366 & 339 & 232 & 248 & 222 \\
\hline Basic & 342 & 397 & 358 & 255 & 301 & 266 \\
\hline
\end{tabular}



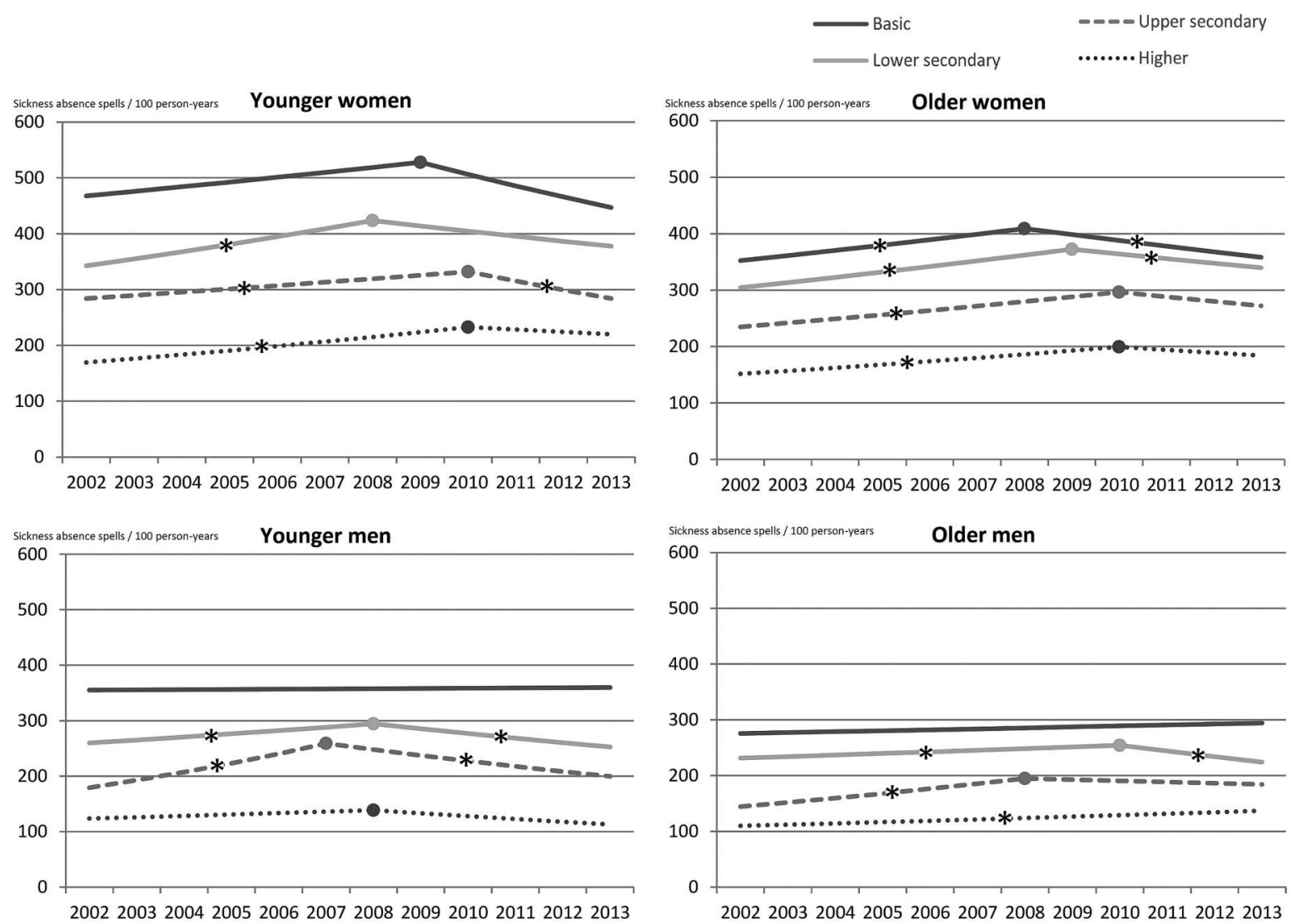

Figure 1 Joinpoint regression-modelled sickness absence spells/100 person-years by age group, gender and education, 2002-2013.

Educational differences in SA trends among men

There was also an evident educational gradient in SA among men in both age groups (figure 1). With regard to younger men, the number of SA spells increased until
2007-2008 and then decreased towards the end of the study period in all educational groups except among those with a basic education (table 3 and figure 1). The trends were somewhat different for older men. The

Table 3 Identified periods (turning points) in sickness absence spells/100 person-years by educational group, 2002-2013

\begin{tabular}{|c|c|c|c|c|}
\hline & \multicolumn{2}{|l|}{ Women } & \multicolumn{2}{|l|}{ Men } \\
\hline & $\begin{array}{l}\text { Identified periods } \\
\text { (turning points) }\end{array}$ & $\begin{array}{l}\text { Annual percentage } \\
\text { change in the identified } \\
\text { period }(95 \% \mathrm{Cl})\end{array}$ & $\begin{array}{l}\text { Identified periods } \\
\text { (turning points) }\end{array}$ & $\begin{array}{l}\text { Annual percentage } \\
\text { change in the identified } \\
\text { period }(95 \% \mathrm{Cl})\end{array}$ \\
\hline \multicolumn{5}{|l|}{ Age 25-34 } \\
\hline \multirow[t]{2}{*}{ Higher } & 2002-2010 & 4.1 (2.2 to 5.9$)$ & 2002-2008 & $1.9(-5.2$ to 9.6$)$ \\
\hline & 2010-2013 & $-1.9(-8.0$ to 4.6$)$ & 2008-2013 & $-4.0(-11.4$ to 4.1$)$ \\
\hline \multirow[t]{2}{*}{ Upper secondary } & 2002-2010 & 2.0 (1.0 to 3.0$)$ & 2002-2007 & 7.7 (2.6 to 13.0$)$ \\
\hline & 2010-2013 & $-5.1(-9.1$ to -0.8$)$ & 2007-2013 & $-4.3(-7.5$ to -0.9$)$ \\
\hline \multirow[t]{2}{*}{ Lower secondary } & 2002-2008 & $3.6(1.6$ to 5.6$)$ & 2002-2008 & $2.1(0.1$ to 4.1$)$ \\
\hline & 2008-2013 & $-2.3(-4.7$ to 0.2$)$ & 2008-2013 & $-3.0(-5.3$ to -0.7$)$ \\
\hline \multirow[t]{2}{*}{ Basic } & 2002-2009 & $1.7(-0.1$ to 3.6$)$ & 2002-2013 & $0.1(-1.1$ to 1.4$)$ \\
\hline & 2009-2013 & $-4.1(-8.8$ to 0.9$)$ & & \\
\hline \multicolumn{5}{|l|}{ Age $35-54$} \\
\hline \multirow[t]{2}{*}{ Higher } & 2002-2010 & 3.5 (1.8 to 5.2$)$ & 2002-2013 & $2.0(1.1$ to 3.0$)$ \\
\hline & 2010-2013 & $-2.7(-9.0$ to 4.2$)$ & & \\
\hline \multirow[t]{2}{*}{ Upper secondary } & 2002-2010 & 3.0 (2.0 to 4.0$)$ & 2002-2008 & 5.1 (2.9 to 7.4$)$ \\
\hline & 2010-2013 & $-2.8(-6.8$ to 1.4$)$ & 2008-2013 & $-1.1(-3.6$ to 1.4$)$ \\
\hline \multirow[t]{2}{*}{ Lower secondary } & 2002-2009 & 2.9 (2.2 to 3.7$)$ & 2002-2010 & $1.2(0.4$ to 2.0$)$ \\
\hline & 2009-2013 & $-2.3(-4.0$ to -0.5$)$ & 2010-2013 & $-4.1(-7.4$ to -0.8$)$ \\
\hline \multirow{2}{*}{ Basic } & 2002-2008 & 2.5 (1.0 to 4.1$)$ & 2002-2013 & $0.6(-0.4$ to 1.6$)$ \\
\hline & 2008-2013 & $-2.6(-4.9$ to -0.2$)$ & & \\
\hline
\end{tabular}


Table 4 The relative index of inequality (RII) for sickness absence spells according to education

\begin{tabular}{|c|c|c|c|c|c|c|}
\hline & \multicolumn{2}{|l|}{2002} & \multicolumn{2}{|l|}{2008} & \multicolumn{2}{|l|}{2013} \\
\hline & RII & $95 \% \mathrm{CI}$ & RII & $95 \% \mathrm{Cl}$ & RII & $95 \% \mathrm{Cl}$ \\
\hline \multicolumn{7}{|l|}{ Age 25-34 } \\
\hline Women & 2.20 & 1.96 to 2.47 & 2.44 & 2.16 to 2.76 & 2.31 & 2.06 to 2.60 \\
\hline Men & 2.76 & 2.18 to 3.49 & 2.12 & 1.68 to 2.69 & 2.26 & 1.79 to 2.84 \\
\hline \multicolumn{7}{|l|}{ Age $35-54$} \\
\hline Women & 2.29 & 2.13 to 2.46 & 2.23 & 2.08 to 2.40 & 2.08 & 1.93 to 2.25 \\
\hline Men & 2.93 & 2.55 to 3.37 & 2.53 & 2.20 to 2.90 & 2.11 & 1.85 to 2.42 \\
\hline
\end{tabular}

turning points were located later among those educated to the upper and lower secondary levels, and there was an increasing trend among the most highly educated throughout the 2002-2013 study period.

The most rapid increase in the amount of SA spells at the beginning of the study period, between 2002 and 2007, was among younger men with an upper secondary education ( $7.7 \%$ annually, CI 2.6 to 13.0$)$, with a rapid decrease between 2007 and 2013 to $-4.3 \%$ annually (CI -7.5 to -0.9 ; table 3 ).

The age-adjusted RII among younger men, in contrast with younger women, was on a higher level at the beginning of the study period and decreased towards the end (table 4): 2.76 (95\% CI 2.18 to 3.49$)$ in $2002,2.12(95 \%$ CI 1.68 to 2.69 ) in 2008 and 2.26 (95\% CI 1.79 to 2.84 ) in 2013. The RII values among older men decreased throughout the study period, from 2002 to 2013.

\section{DISCUSSION}

Our aim was to examine trends in educational differences in SA among female and male employees aged 25-34 years in 2002-2013, and to assess the magnitude of the educational differences. The main findings were as follows: (1) SA levels first increased and then decreased in all educational groups among younger and older women and in most groups among younger and older men, the turning points in the trends being located between 2007 and 2010; (2) the magnitude of the relative differences measured by the RII remained broadly stable among younger women but decreased among younger men. Among older employees, the RII values decreased throughout the 2002-2013 study period, particularly among men. Thus, the educational differences in SA were larger among men than women at the beginning of the study period, and of similar magnitude towards the end.

There was a clear educational gradient among female and male employees, those with a basic education having the most SA and the highly educated the least, as expected. This finding is in line with the results of previous studies covering broader age ranges and older adults. ${ }^{4}$ 17-19 Education is a key dimension of socioeconomic position ${ }^{20}$ and in itself has an effect on ill health and SA that is partly mediated through occupational class and income. ${ }^{7} \quad 10 \quad 21$ A higher level of education provides knowledge, skills, values and attitudes that are likely to support healthier choices. ${ }^{9}$

Education affects SA to some extent through occupational class, which reflects working conditions. ${ }^{7} 21$ Differences between occupational classes are well established: SA is more prevalent among those in lower as opposed to higher level occupations. ${ }^{17} 22-26$ We found in our previous study of employees aged 25-59 years that the amount of medically certified SA among manual workers was two to three times higher than among managers and professionals. ${ }^{4}$ Occupational class is indicative of the working environment and thereby affects health and SA. ${ }^{27} 28$ Previous studies covering broader age ranges have shown that physical working conditions in particular explain differences in SA between occupational classes. ${ }^{25} 29$ Occupations in which employees are under a lot of strain but have little control over their jobs also carry a higher risk of SA. ${ }^{30} 31$

Educational level, through occupational class, is a strong determinant of income, ${ }^{9}$ which reflects access to material resources ${ }^{8}$ such as those required to buy healthier food, and allows access to services and health-related leisure activities. ${ }^{9}$ As are other socioeconomic indicators, low income is associated with high SA. 3233

A number of other factors, such as social and health-related selection to education, may also influence the association between educational level and SA. Children of parents in a low socioeconomic position may end up on lower educational tracks. ${ }^{34}$ A lower level of education may lead to later adverse health behaviours and inadequate material and non-material resources, ${ }^{34} 35$ and to employment in lower occupational classes entailing physical and psychosocial work exposures. ${ }^{27} \quad 28$ Health-related selection, as well as health problems during childhood and youth, may contribute to educational differences in SA among young employees.

The turning points in the SA trends in 2007-2010 could be attributable in part to upstream economic factors and policies implemented within the City of Helsinki. Finland went into an economic downturn in 2008, and this may have caused job insecurity with its potential contribution to SA. Employees on fixed-term contracts might experience job insecurity, and this may have lowered the SA rates because of fear of a job loss. Conversely, job insecurity potentially encourages sickness presenteeism. ${ }^{36}$ It may also contribute to ill health and 
SA via increasing demands and stress, given that the remaining employees may suffer from work overload due to organisational changes and new job requirements. ${ }^{37}$

The City of Helsinki offers similar occupational health services to all its employees. A specific preventive focus was adopted within its administrative departments in 2007 . $^{38}$ The aim was to provide support and comprehensive occupational health services to superiors with a view to enhancing their work ability and their potential to support their subordinates and thereby reduce ill health and SA in the workplace. Superiors are also required to discuss SA with their subordinates when spells or days of absence reach a certain level. ${ }^{38}$ These measures may have influenced SA levels and could explain some of the decrease after 2007. However, this intervention had no focus on educational variation in SA.

The magnitude of educational differences in SA remained broadly stable among younger women and decreased slightly among older women and more strongly among men towards the end of the study period. Thus, the educational differences were stronger among younger and older men than among women at first, but similar at the end of the period. Previous studies representing adults in a broader age range report steeper socioeconomic differences in SA among men. ${ }^{72529} 39$ The participants of this study shared equal SA policies that did not change drastically during the study period. Towards the end, the numbers of people with a basic education declined in both age groups among women and men. It is therefore possible that there was some form of educational selection during the economic downturn, ${ }^{40}$ and that the educational level has risen particularly among younger employees. This might have influenced the magnitude of educational differences in SA.

\section{Methodological considerations}

This study was based on a large number of younger and older employees of the City of Helsinki. Information on their education was drawn from Statistics Finland's register of completed education and qualifications, which is a complete and accurate national register that includes the highest degree or the most recent qualification and is updated annually. The SA registers used were held by the employer and constituted a reliable and comprehensive data source. However, they lack further information on the participants and their health-related background.

Using education as a measure of socioeconomic position among young employees has many advantages: it is hierarchical and determined in early adulthood, and most aged over 25 years have finished their educational career. Once established, the level of education is not subject to major change. ${ }^{20}$ However, the number of young employees in the higher educational groups was relatively small.

Joinpoint modelling enabled us to identify turning points in recent SA trends. However, in the case of younger men in particular, the small number of participants with a higher or basic level of education affected the statistical power to detect changes in these trends.

We used RII to examine the relative educational differences, as recommended when making comparisons over time. One of the advantages is that it takes into account the different amounts of SA in all groups, and also the relative size and position of each one. ${ }^{16}$

The participants in our study were municipal employees of a single employer. The results could be generalised with caution to the Finnish municipal sector, but not to the labour force in general.

\section{CONCLUSIONS}

We found a clear educational gradient in SA among younger and older women and men. Spells of SA increased in the early 2000s, and the turning points to decline were located in the economic downturn, between 2007 and 2010 in all educational groups among younger and older women, and in most groups among younger and older men.

The magnitude of the educational differences remained broadly stable among younger women, decreasing slightly among older women and more strongly among younger and older men towards the end of the study period. Thus, the educational differences were greater among men than women at the beginning, but similar at the end.

Our findings suggest that preventive measures are needed among young employees in general, and among those with a low level of education in particular. Early prevention helps extend working careers and reduce costs related to work disability. Educational attainment should be promoted.

Acknowledgements The authors wish to thank the City of Helsinki.

Contributors HS interpreted the results and drafted the manuscript. HS and $\mathrm{OP}$ carried out the statistical analyses. EL, JL, OP and OR contributed to designing the study, interpreting results and drafting the manuscript. All the authors critically reviewed the manuscript and approved the final version.

Funding HS was supported by the Doctoral Programme in Population Health, University of Helsinki. EL and OP were supported by the Academy of Finland (grant number 1257362). OR was supported by the Finnish Work Environment Fund (grant number 112231).

Competing interests None declared.

Patient consent Obtained.

Ethics approval The ethics committees of the Department of Public Health, the University of Helsinki, and the health authorities of the City of Helsinki.

Provenance and peer review Not commissioned; externally peer reviewed.

Data sharing statement Data are available upon request. The research team does not have the permission to release the data to third parties. Permission can be applied from the register holding authorities by first contacting data management of the Helsinki Health Study (kttl-hhs@helsinki.fi).

Open Access This is an Open Access article distributed in accordance with the Creative Commons Attribution Non Commercial (CC BY-NC 4.0) license, which permits others to distribute, remix, adapt, build upon this work noncommercially, and license their derivative works on different terms, provided the original work is properly cited and the use is non-commercial. See: http:// creativecommons.org/licenses/by-nc/4.0/ 


\section{REFERENCES}

1. Lorant $\mathrm{V}$, Deliège $\mathrm{D}$, Eaton $\mathrm{W}$, et al. Socioeconomic inequalities in depression: a meta-analysis. Am J Epidemiol 2003;157:98-112.

2. Mackenbach JP. Socio-economic health differences in the Netherlands: a review of recent empirical findings. Soc Sci Med 1992;34:213-26.

3. Nielsen ML, Rugulies R, Christensen KB, et al. Psychosocial work environment predictors of short and long spells of registered sickness absence during a 2-year follow up. J Occup Environ Med 2006;48:591-8.

4. Piha K, Martikainen $\mathrm{P}$, Rahkonen $\mathrm{O}$, et al. Trends in socioeconomic differences in sickness absence among Finnish municipal employees 1990-99. Scand J Public Health 2007;35:348-55.

5. Aaviksoo E, Baburin A, Kiivet RA. Risk factors for sickness absence among Estonian employees. Occup Med (Lond) 2013;63:156-9.

6. Robroek SJ, van Lenthe FJ, Burdorf $A$. The role of lifestyle, health, and work in educational inequalities in sick leave and productivity loss at work. Int Arch Occup Environ Health 2013;86:619-27.

7. Piha K, Laaksonen M, Martikainen $\mathrm{P}$, et al. Interrelationships between education, occupational class, income and sickness absence. Eur J Public Health 2010;20:276-80.

8. Laaksonen M, Rahkonen O, Martikainen P, et al. Socioeconomic position and self-rated health: the contribution of childhood socioeconomic circumstances, adult socioeconomic status, and material resources. Am J Public Health 2005:95:1403-9.

9. Galobardes B, Shaw M, Lawlor DA, et al. Indicators of socioeconomic position (part 1). J Epidemiol Community Health 2006;60:7-12.

10. Sumanen $\mathrm{H}$, Pietiläinen $\mathrm{O}$, Lahti J, et al. Interrelationships between education, occupational class and income as determinants of sickness absence among young employees in 2002-2007 and 2008-2013. BMC Public Health 2015;15:332.

11. Koopmans PC, Roelen CA, Groothoff JW. Frequent and long-term absence as a risk factor for work disability and job termination among employees in the private sector. Occup Environ Med 2008;65:494-9.

12. Lahelma $\mathrm{E}$, Aittomäki A, Laaksonen $\mathrm{M}$, et al. Cohort profile: the Helsinki Health Study. Int J Epidemiol 2013;42:722-30.

13. Statistics Finland. Registers of completed education and degrees http://www.stat.fi/meta/rekisteriselosteet/rekisteriseloste_ tutkintorekisteri.html (accessed 15 Mar 2015).

14. Kim HJ, Fay MP, Feuer EJ, et al. Permutation tests for joinpoint regression with applications to cancer rates. Stat Med 2000;19:335-51.

15. National Cancer Institute. Joinpoint regression program. April 2014. http://surveillance.cancer.gov/joinpoint/ (accessed 1 Mar 2015).

16. Shaw M, Galobardes B, Lawlor DA, et al. The handbook of inequality and socioeconomic position. Concepts and measures. Bristol: The Policy Press, 2007.

17. Lund $\mathrm{T}$, Labriola M, Villadsen $\mathrm{E}$. Who is at risk for long-term sickness absence? A prospective cohort study of Danish employees. Work 2007;28:225-30.

18. Beemsterboer W, Stewart R, Groothoff J, et al. A literature review on sick leave determinants (1984-2004). Int J Occup Med Environ Health 2009;22:169-79.

19. Henderson M, Clark C, Stansfeld S, et al. A lifecourse approach to long-term sickness absence--a cohort study. PLOS ONE 2012;7: e36645.

20. Krokstad S, Kunst AE, Westin S. Trends in health inequalities by educational level in a Norwegian total population study. $J$ Epidemiol Community Health 2002;56:375-80.

21. Lahelma E, Martikainen $\mathrm{P}$, Laaksonen $\mathrm{M}$, et al. Pathways between socioeconomic determinants of health. J Epidemiol Community Health 2004;58:327-32.
22. North F, Syme SL, Feeney A, et al. Explaining socioeconomic differences in sickness absence: the Whitehall II study. BMJ 1993;306:361-6.

23. Moncada S, Navarro A, Cortes I, et al. Sickness leave, administrative category and gender: results from the "Casa Gran" project. Scand J Public Health Suppl 2002;59: 26-33.

24. Borg K, Hensing G, Alexanderson K. Prediction of future low levels of sickness absence among young persons sick listed with back neck, or shoulder diagnoses. Work 2004;23:159-67.

25. Laaksonen M, Piha K, Rahkonen O, et al. Explaining occupational class differences in sickness absence: results from middle-aged municipal employees. J Epidemiol Community Health 2010;64:802-7

26. Hilla $S$, Jouni L, Eero L, et al. 12-year trends in occupational class differences in short sickness absence among young women. Scand J Public Health 2015;43:441-4.

27. Vahtera J, Virtanen P, Kivimäki M, et al. Workplace as an origin of health inequalities. $J$ Epidemiol Community Health 1999;53:399-407.

28. Christensen KB, Labriola M, Lund $\mathrm{T}$, et al. Explaining the social gradient in long-term sickness absence: a prospective study of Danish employees. J Epidemiol Community Health 2008;62:181-3.

29. Hansen $\mathrm{H}$, Ingebrigtsen $\mathrm{T}$. Social class and sickness absence in Norway. Acta Sociologica 2008;51:309-27.

30. Lund T, Labriola M, Christensen KB, et al. Psychosocial work environment exposures as risk factors for long-term sickness absence among Danish employees: results from DWECS/DREAM. J Occup Environ Med 2005;47:1141-7.

31. Lund T, Labriola M, Christensen KB, et al. Physical work environment risk factors for long term sickness absence: prospective findings among a cohort of 5357 employees in Denmark. BMJ 2006;332:449-52.

32. Kivimäki M, Vahtera J, Thomson L, et al. Psychosocial factors predicting employee sickness absence during economic decline. $J$ Appl Psychol 1997;82:858-72.

33. Löve J, Holmgren $\mathrm{K}$, Torén $\mathrm{K}$, et al. Can work ability explain the social gradient in sickness absence: a study of a general population in Sweden. BMC Public Health 2012;12:163.

34. Kestilä L, Martelin T, Rahkonen O, et al. The contribution of childhood circumstances, current circumstances and health behaviour to educational health differences in early adulthood. BMC Public Health 2009;9:164.

35. Conti G, Heckman JJ. Understanding the early origins of the education-health gradient: a framework that can also be applied to analyze gene-environment interactions. Perspect Psychol Sci 2010:5:585-605.

36. Heponiemi T, Elovainio M, Pentti J, et al. Association of contractual and subjective job insecurity with sickness presenteeism among public sector employees. J Occup Environ Med 2010;52:830-5.

37. Blekesaune M. Job insecurity and sickness absence: correlations between attrition and absence in 36 occupational groups. Scand J Public Health 2012;40:668-73.

38. City of Helsinki. Henkilöstöraportti 2007 (staff report) (in Finnish). Helsinki: Helsingin kaupunginkanslia, 2008.

39. Löve J, Hensing G, Holmgren K, et al. Explaining the social gradient in sickness absence: a study of a general working population in Sweden. BMC Public Health 2013;13:545.

40. Helgesson $\mathrm{M}$, Johansson $\mathrm{B}$, Nordqvist $\mathrm{T}$, et al. Unemployment at a young age and later sickness absence, disability pension and death in native Swedes and immigrants. Eur J Public Health 2013;23:606-10. 